\title{
Entre os acertos e desacertos do curso de pedagogia no Brasil: reflexões sobre a necessidade de articulação com as demandas do mundo da vida
}

\author{
Catia Piccolo Viero Devechi* \\ Gionara Tauchen** \\ Amarildo Luiz Trevisan ${ }^{* * *}$
}

\begin{abstract}
Resumo
O presente artigo, de natureza hermenêutico-reconstrutiva, discute a identidade profissional do pedagogo a partir da constituição do curso de Pedagogia, tensionado entre docência, território da formação de professores ou área do conhecimento. Primeiramente, aborda a proposta como possibilidade de repensar a trajetória do curso comunicativamente por meio da referência aos elementos constitutivos do mundo da vida (reprodução cultural, integração social e socialização). A seguir, apresenta o histórico e a trajetória das discussões acerca do curso de Pedagogia no Brasil com ênfase na institucionalização das suas Diretrizes. Por fim, discute o alicerce do mundo da vida de maneira crítica às prerrogativas guiadas apenas por interesses de discursos para auxiliar no questionamento de algumas certezas que acabaram prevalecendo na definição dos rumos do curso de Pedagogia.
\end{abstract}

\section{Palavras chave}

Pedagogia, agir comunicativo, Mundo da vida.

Recepció original: 31 de març de 2021

Acceptació: 2 de maig de 2021

Publicació: 1 de juliol de 2021

\section{Introdução'}

As Diretrizes Curriculares para o curso de Pedagogia (2006) foram resultado de diversos debates entre diferentes perspectivas interpretativas do campo educacional sobre questões recorrentes ao longo da sua história, realizados por pesquisadores ligados às diversas entidades acadêmicas. Porém, embora realizadas diferentes discussões envolvendo essas entidades e atores sociais, as ambiguidades e indefinições das Diretrizes aprovadas não esgotaram o debate. $O$ curso de Pedagogia ainda é objeto de discussão e polêmica porque alguns defendem que as Diretrizes avançaram na questão da docência como pilar da formação do pedagogo, alertando, entretanto, que é preciso ter prudência na sua aplicação, tendo em vista o conceito de docência ampliado engloba o pesquisador e o gestor para espaços escolares e não-escolares. Outros defendem que tais Diretrizes apontam um equívoco ao reduzir a Pedagogia à docência e ao estabelecer que um único curso seria capaz de abarcar diferentes modalidades.

${ }^{*}$ ) Professora de la Universidade de Brasília (Brasil). Correio eletrônico: catiaviero@gmail.com

$\left.{ }^{* *}\right)$ Professora de la Universidade de Rio Grande (Brasil). Correio eletrônico: giotauchen@gmail.com

${ }^{(* *)}$ Professora de la Universidade Federal de Santa Maria (Brasil). Correio eletrônico: trevisanamarildo@gmail.com

(1) A pesquisa conta com auxílio do CNPq - Processo: (431641/2018-8) e da FAPDF - Protocolo: (22660.93.33005.30052018). 
Em linhas gerais, especialistas que participaram da elaboração das propostas como Brzezinski (2013), Aguiar et al. (2006), Scheibe (2011; 2007), Silva (2006) sustentam a docência como base comum dessa formação. Scheibe (2007) comenta que esta foi uma trajetória longa, mas que se encontra ainda inconclusa, reafirmando a ideia da docência como pilar da formação: «A docência como base, tanto da formação quanto da identidade dos profissionais da educação, insere-se na sua compreensão como ato educativo intencional voltado para o trabalho pedagógico escolar ou não-escolar» (p. 59). Outros autores, como Libâneo (2013) e Franco, Libâneo e Pimenta (2007) defendem a posição de que a Pedagogia deveria ser a base da formação e da atuação profissional do professor de modo geral, e não o contrário. Além desses, Saviani (2012), Gatti (2010) e Cruz (2011) também se posicionaram criticamente em torno das proposições das Diretrizes Curriculares para esta formação.

A compreensão sugerida pelos especialistas é a de que o modo como os acertos sobre as Diretrizes do curso de pedagogia foram realizados, bem como as decisões tomadas avançam a discussão no sentido da profissionalização do pedagogo. Mas, mesmo assim, ainda não condizem com as necessidades das práticas vividas, tendo em vista as dificuldades na implementação da proposta e a ampliação da crise de identidade do pedagogo. As Diretrizes, como foram apresentadas, não equacionaram o problema da formação de professores para os anos iniciais e educação infantil, nem das demais modalidades pedagógicas escolares e não-escolares e, menos ainda, dirimiram as dúvidas em torno da falta de conteúdo próprio da Pedagogia.

Neste sentido, intencionando uma aprendizagem sobre o curso de Pedagogia mais atento às práticas cotidianas, perguntamos: será que a referência aos critérios de universalidade do mundo da vida poderia auxiliar no esclarecimento dos debates de forma a permitir acordos mais amplamente aceitos? Estes acordos poderiam estar voltados não somente ao atendimento das demandas já produzidas até aqui, mas também das necessidades da reprodução e socialização crítica do mundo vivo?

Tal referência nos traz a compreensão de que os acordos devem contemplar a interrelação de interesses particulares ou locais com a amplitude da universalidade do campo, necessária a qualquer tentativa de comunicação voltada ao entendimento sobre questões práticas. É isso o que defende Göergen (2008) quando pensa esta relação na educação superior:

\footnotetext{
hoje, não há mais instituições de ensino superior que tenham vocação apenas regional ou local em sentido estrito. O universal e o local imbricam-se de tal modo que já não se pode falar de ciência local, nem ensino local, nem formação local. O local sempre deve preservar a perspectiva universal e o universal sustentar-se no local. (Göergen, 2008, p. 811)
}

Desse modo, o conhecimento legítimo não seria alcançado exclusivamente pela justificação, pois requereria dessa o atendimento às exigências da experiência prática. Para Habermas (2012), é o distanciamento dos elementos constitutivos do mundo vivido que entrava a aprendizagem dialógica, sendo difícil o acordo por meio de uma aceitabilidade mais ampliada. $\mathrm{O}$ mundo da vida para ele «é o contrapeso conservador que se opõe ao risco do dissenso, que surge com todo o processo atual de entendimento» (Habermas, 2012, p. 139). Entende que não é possível avançar no tratamento de questões problemáticas sem fazer referência aos significados e regras já aceitos pela tradição, no cotidiano da integração social e de socialização. 
O objetivo desse artigo é repensar o equacionamento das dificuldades de uma aprendizagem comunicativa sobre o curso de Pedagogia, apostando nas possibilidades de acordo diante das exigências do campo pedagógico escolar e não-escolar e da sua área como campo de conhecimento específico. Nos utilizaremos da abordagem hermenêutico-reconstrutiva, de Habermas, fazendo algumas reflexões a partir de documentos históricos referentes ao curso e das discussões de autores abalizados sobre o tema das Diretrizes da Pedagogia.

Não estamos propondo o universo da reflexão habermasiana como solução para os problemas apresentados na trajetória recente do curso de pedagogia. Menos ainda queremos reduzir a complexidade de uma teoria, como a da ação comunicativa, à prática pedagógica. Antes disso, interessa contribuir com a sua teoria para elucidar melhor a compreensão da trajetória do curso, especialmente na ampliação da inclusão dos três pilares do mundo da vida (reprodução cultural, integração social e socialização) como constituintes da formação. $E$ isso vai ao encontro do que Mühl salienta a respeito dessa teoria, como «a necessidade de que todo conhecimento seja entendido como parte do mundo da vida» (Mühl, 2010, p. 245), o que alavanca desse modo a possibilidade de a Pedagogia se manter como um saber válido diante dos desafios da formação frente à complexidade do contemporâneo.

O artigo está organizado em três momentos: $1^{\circ}$ ) analisamos a proposta nesse cenário, como possiblidade de pensar as suas bases comunicativamente, por meio da referência ao conceito que abarca as nossas vivências, de maneira crítica às prerrogativas guiadas apenas por interesses estratégicos específicos; $2^{\circ}$ ) apresentamos uma breve reconstrução da trajetória das discussões e das legislações acerca do curso de Pedagogia no Brasil, no sentido de explicitar os possíveis acertos e os prováveis desacordos existentes nas deliberações de suas diretrizes; e, por fim (3०), procuramos fazer uma problematização desses consensos na condução do curso até o presente, inspirados na teoria da ação comunicativa.

\section{Os acertos comunicativos articulados ao mundo da vida}

Para Aguiar et al (2006, p. 821), os diferentes sentidos dados historicamente à pedagogia e ao curso de pedagogia materializados no currículo expressam abordagens sobre teoria-prática, conteúdo-forma e objeto-sujeito e reportam-se às questões epistemológica e socioculturais que permeiam o debate sobre a modernidade. Ora, um dos autores que levou adiante um produtivo debate sobre a modernidade, nos últimos tempos, foi o filósofo alemão Jürgen Habermas. Contra a concepção de um certo movimento pós-moderno de cunho conservador, que considerava a modernidade algo que deveríamos deixar para trás, ele pronunciou, ainda no início dos anos 80 do século passado, na ocasião em que recebeu o prêmio Adorno da cidade de Frankfurt, um célebre discurso considerando a modernidade um projeto ainda inconcluso. A teoria da ação comunicativa, de Habermas (2012), tem a ver com os grandes acordos que normatizam o viver coletivo moderno em um mundo globalizado. Porém, proporcionando o reconhecimento do caráter universal das necessidades da área, pode motivar a rearticulação das formas de acertos no campo da pedagogia, evitando a sua redução instrumental, as quais devem ser garantidas pela coerência prática diante da diversidade de interpretações. 
O agir comunicativo, associado ao mundo das vivências dos indivíduos, admite incorporar a pluralidade de interpretações sobre o assunto, impedindo que as decisões fiquem presas na sua dimensão operacional. Isso porque o ancoramento nas dimensões culturais, sociais e pessoais reativa o compromisso mais alargado com a noção de prática, que envolve a tradição, reincorporando as dimensões da vida ao campo de conhecimento. Não é possível, segundo o autor, reduzir a compreensão social à complexidade do universo sistêmico. É necessário articular as duas vertentes de compreensão de forma que possamos saturar as tendências egoístas, individualistas e dominadoras no que se refere aos acertos sociais em torno das necessidades práticas. Para que as compreensões possam ser validadas diante do outro e ganhar universalidade, os sujeitos devem, embora indiretamente, fazer referência a três relações com o mundo da vida: 1) o mundo objetivo, como totalidade das entidades sobre as quais são possíveis enunciados verdadeiros; 2 ) mundo social, como totalidade das relações interpessoais reguladas; 3) mundo subjetivo, que é totalidade das vivências em que o falante tem acesso privilegiado e pelo qual pode manifestar-se com veracidade diante de um público. Fazendo referências aos três mundos, podemos interpretar e elaborar definições comuns relativas à situação da ação. (Habermas, 2012)

As situações novas emergem desse universo «que se constrói sobre um estoque do saber cultural com o qual estamos familiarizados» (Habermas, 2012, p. 230), não sendo possível se desvencilhar dele, sendo seu objetivo fixar as formas da intersubjetividade do entendimento. É nele que os sujeitos se encontram, podendo levar a pretensões de que suas falas condizem com o mundo objetivo, social e subjetivo, e assim criticar ou confirmar as pretensões de validade. Quando as certezas do mundo da ação se tornam problemáticas, elas migram para o discurso a fim de ser confrontadas no diálogo junto à esfera pública. No entanto, isso não é tudo, não basta que haja a justificação do saber pela via discursiva, uma vez que podemos nos enganar e aceitar visões parciais ou distorcidas da realidade.

Ou seja, embora o critério da inteligibilidade e a expressão clara do sentido devam ser considerados como aspectos preliminiares indispensáveis do processo do entendimento, eles, por si mesmos, não garantem a validação de um determinado conhecimento ou um determinado valor (Mühl, 2010, pp. 244-245)

Dessa maneira, o agir comunicativo permite uma dupla possibilidade para repensar os processos educativos, uma vez que toda deliberação pode ser entendida como falível e, portanto, sujeita a uma hermenêutica constante. Porém, não basta a elevação do problema à deliberação discursiva, mas é preciso colocar o saber sob a chancela da sua eficácia pragmática, isto é, «de se manter como um saber válido na produção e reprodução do mundo da vida» (Mühl, 2010, p. 245). Por isso, acreditamos que o agir comunicativo se coloca como uma possibilidade de esclarecimento para recondução das discussões sobre educação de modo geral e, no caso específico, também para repensar a trajetória do curso de Pedagogia no Brasil.

\section{Breve trajetória do curso de Pedagogia às Diretrizes Curriculares}

Foi no contexto de pluralidade dos currículos de curso de Pedagogia, da necessidade de se firmar frente aos Institutos Superiores de Educação, das exigências de melhoria da escola básica, que as Diretrizes Curriculares Nacionais passaram a ser discutidas. A Lei $\mathrm{n}$. 9.394/96, embora não atendesse todas as reivindicações do movimento nacional, introduziu algumas mudanças na formação dos profissionais de educação da Educação Básica. O artigo 62 apresentou os Institutos Superiores de Educação como outra possi- 
bilidade para formação desses profissionais além do curso de Pedagogia, admitindo como formação mínima para o exercício do magistério na Educação Infantil e nos cinco primeiros anos do Ensino Fundamental, o curso oferecido na modalidade normal (Brasil, 1996). No artigo 63 é indicado que uma das tarefas dos Institutos se destina à formação de professores para a Educação Infantil e para as Séries Iniciais. (Brasil, 1996). O curso de Pedagogia parecia ter perdido a sua função na formação de professores, tornando-se pauta de diversas discussões polêmicas. Talvez essa fase tenha sido a mais difícil dos cursos de Pedagogia, pois os Institutos Superiores de educação passaram a ter a mesma responsabilidade na formação dos professores, o que poderia significar o desaparecimento gradativo desses cursos na universidade.

Em relação à formação de profissionais de educação para a administração, planejamento, inspeção, supervisão e orientação educacional para a Educação Básica, o artigo 64 diz que deverá será feita em «cursos de graduação em Pedagogia ou em nível de pós-graduação, a critério da instituição de ensino, garantida, nesta formação, a base comum nacional» (Brasil, 1996, p. 26). Entretanto, ressalta que todos os profissionais da educação devem possuir formação docente. Segundo o art. 67 «a experiência docente é a condição para o exercício de qualquer outra função do magistério». (Brasil, 1996, p. 27)

O Ministério da Educação, por intermédio da Secretaria de Educação Superior, abriu o edital n. 4/1997 para que fossem encaminhadas propostas para a elaboração das Diretrizes Curriculares dos cursos superiores. A elaboração das Diretrizes foi atribuída às comissões de especialistas do ensino das diferentes áreas do conhecimento, nomeadas pelo SESU/MEC, entre essas da Pedagogia. A solicitação do Ministério representou a possibilidade de as universidades indicarem propostas segundo as suas interpretações acerca dos artigos da LDB referentes aos profissionais da educação.

A comissão de especialistas do ensino de Pedagogia de $1998^{2}$ (CEEP) passou a organizar as contribuições das instituições com a tarefa de pensar a formação dos educadores para a escola básica e administrar os conflitos acerca das diferentes posições das IES referentes às responsabilidades formativas do curso de Pedagogia, além das posições contrárias à criação dos institutos. Na sequência, a comissão passou a receber contribuições também de outras entidades nacionais, entre elas a Anfope -Associação Nacional pela Formação Profissional da educação (Silva, 2006).

As sugestões da Anpofe voltaram-se para a concepção de uma escola única de formação do professor, sugerindo uma base comum nacional. Desde 1995, a associação encaminha suas formulações na direção de uma política educacional global de formação e profissionalização do magistério, que trataria principalmente, da formação inicial, condições de trabalho, salário, carreira e formação continuada (Anfope, 1998). A associação elaborou o documento intitulado Proposta de diretrizes curriculares nacionais para os cursos de formação dos profissionais da educação, no qual indica que a formação dos profissionais da educação para a escola básica deveria se dar nas universidades e centros de educação (Anfope, 1998). A Associação defendeu ainda a manutenção do curso de Pedagogia, a superação da fragmentação entre as habilitações, propondo que a organização curricular acontecesse sob orientação das próprias instituições formadoras

(2) Nomeada em 1998, esta comissão foi constituída pelos seguintes professores: Celestino Alves da Silva Junior (UNESP-Marília), Leda Scheibe (UFSC), Márcia Angela de Aguiar da UPF, Tizuko Morchida Kishimoto da USP, Zélia Mileo Pavão da PUC-Paraná. 
orientadas por indicações globais, como a base comum nacional, e a consideração da docência como base da identidade de todos os profissionais da educação (Silva, 2006)

Além da Anfope, outros grupos (Associação Nacional de Pós-Graduação e pesquisa em Educação-Anped, Associação Nacional de Política e Administração da EducaçãoAnpae, Centro de Estudos de Educação e Sociedade-Cedes, Fórum Nacional de Diretores de Faculdades, Centro de Educação ou Equivalentes das Universidades Públicas Brasileiras-Forumdir) também foram ouvidos pela comissão de especialistas do ensino de Pedagogia. Em 1999, foi encaminhado ao Conselho Nacional de Educação-CNE o documento intitulado Proposta de Diretrizes Curriculares, voltado a uma concepção de curso aberto a várias áreas profissionais de atuação do pedagogo, tornando a docência a base obrigatória da formação. Tratou-se de uma proposta de ampliação do campo de atuação do pedagogo para áreas emergentes do campo educacional (Silva, 2006). Tal documento foi bem recebido pela comunidade acadêmica e contemplou as tendências conflitantes dessas entidades no que se refere às funções do curso. No entanto, o documento não foi encaminhado, sendo enviada pelo Ministério da Educação outra versão ao CNE, aprovada por meio do parecer n. 009/2001, intitulado Diretrizes para os Cursos de Formação Inicial de Professores para a Educação Básica, que levou à promulgação da Resolução CNE/CP no 1, de 18 de fevereiro de 2002, instituindo as Diretrizes Curriculares Nacionais para a Formação de Professores da Educação Básica ${ }^{3}$, em nível superior, curso de licenciatura, de graduação plena.

Segundo Aguiar et al. (2006), já naquele momento a Anfope e a comissão de especialistas de Pedagogia, da SESU/MEC, apontavam com clareza a necessidade de tratar, simultaneamente e de forma integrada, a formação de todos os profissionais da educação, licenciados e pedagogos. A recusa do documento de 1999 pelo MEC foi sempre uma tônica dos debates e embates.

Explicando melhor como se deu esse processo, em dezembro de 1999, por meio do Decreto presidencial de n. 3.276, a formação de docentes para os anos iniciais do Ensino Fundamental e para a Educação Infantil, quando em nível superior, deveria ser exclusiva dos cursos normais superiores, restando, portanto, ao curso de Pedagogia a formação de qualquer outro profissional que não o professor. Diante de muita resistência da comunidade acadêmica, outro decreto foi publicado no ano seguinte, o de $n^{\circ}$ 3.554/2000, substituindo o termo exclusivamente pelo preferencialmente. Tal substituição possibilitou que tanto o curso de Pedagogia quanto os cursos normais superiores formassem professores para a Educação Infantil e para os anos iniciais do Ensino Fundamental.

Tomando como base os documentos encaminhados ao CNE por entidades envolvidas na discussão (Anfope, Anped, Anpae, Cedes e Forumdir) e reafirmando a necessidade do estabelecimento de Diretrizes Nacionais específicas para os cursos de Pedagogia, conforme já apresentada pela comissão de 1999, a nova comissão (2000-2002) de espe-

(3) As Diretrizes Curriculares Nacionais para a Formação de Professores da Educação Básica, aprovadas em 2002 , constituiram-se em um conjunto de princípios, fundamentos e procedimentos a serem observados na organização institucional e curricular dos cursos de licenciatura para as etapas e modalidades da educação básica (Brasil, 2002). Tais diretrizes foram ancoradas na noção de competência, e desse modo, na organização mais flexível e interdisciplinar de conteúdos, do tempo e dos espaços educacionais, sendo atribuída às instituições de ensino superior a responsabilidade com a preparação inicial dos profissionais do magistério para a escola básica. 
cialistas para o ensino de Pedagogia 4 elabora a proposta de Diretrizes Curriculares Nacionais para o curso de graduação em Pedagogia. Tal demanda ocorreu em atendimento à solicitação da comissão especial do Conselho Nacional de Educação, encarregada de estabelecer as Diretrizes para esse curso.

Essa proposta foi fruto de discussões e de decisões políticas consolidadas entre os anos 80 e 90 no âmbito das faculdades/centros de educação das universidades, como a compreensão de que o curso de Pedagogia é o espaço para a formação dos profissionais da educação para a atuar na Educação Infantil, anos iniciais e nos cursos normais. Segundo a Comissão (2000-2002), «o eixo da formação do pedagogo é o trabalho pedagógico escolar e não-escolar, que tem na docência, compreendida como ato educativo intencional, o seu fundamento» (CEEP, 2002, p. 4). A base da formação deve ser a docência considerada no seu sentido amplo, «no interior de um projeto formativo e não numa visão reducionista que a configure como um conjunto de métodos e técnicas neutros, descolado de uma dada realidade histórica» (CEEP, 2002, p. 4). O curso de Pedagogia deve ser ao mesmo tempo uma licenciatura e um bacharelado. A comissão (2002) se utiliza da compreensão de trabalho pedagógico do Forundir:

ao compreendê-lo como práxis educativa, uma unidade teórico-prática e unitária, porquanto não suporta parcelarizações, rejeita-se qualquer processo de formação que tome como referência "competências» definidas a partir da prévia divisão dos espaços e tarefas dos processos educativos (p. 5).

O egresso do curso de Pedagogia deverá estar em condições de atuar na:

\begin{abstract}
1. Docência na Educação Infantil, nas Séries Iniciais do Ensino Fundamental (nas diversas modalidades, tais como escolarização de crianças, jovens e adultos; Educação Especial; Educação Indígena) e nas disciplinas pedagógicas para a formação de professores (conteúdos específicos da docência e do processo de ensino e aprendizagem em diferentes âmbitos: Curso Normal em nível médio e superior, programas especiais de formação pedagógica, programas de educação continuada, etc.) destaca-se que a atuação do pedagogo em nível superior - Normal Superior e Licenciaturas, supõe a necessária qualificação profissional em nível de pós-graduação; 2. Gestão educacional, entendida como a organização do trabalho pedagógico em termos de planejamento, coordenação, acompanhamento e avaliação nos sistemas de ensino e nos processos educativos formais e não formais; 3. Produção e difusão do conhecimento científico e tecnológico do campo educacional; 4. Atuação docente/técnica em áreas emergentes no campo educacional, em função dos avanços teóricos e tecnológicos. (CEEP, 2002, p. 6)
\end{abstract}

A Comissão de especialistas (2002) ainda retoma do Forumdir, a compreensão de trabalho pedagógico: a «forma de conceber que toma a ação docente como fundamento do trabalho pedagógico, determina que os processo de formação dos profissionais da educação tenham organicidade a partir de uma base comum - os processos educativos em sua dimensão de totalidade sobre o qual dar-se-ão os recortes específicos, em termos de aprofundamento» (CEEP, 2002, p. 5).

A Comissão (2002) ressalta a ampla possibilidade de formação no curso de Pedagogia, devendo os recortes ser feitos pelas instituições formadoras a partir das suas condições específicas, dentre essas o corpo docente qualificado, a capacidade de desenvolver pesquisa e uma infraestrutura adequada. Não se trata de abranger todas as opções, mas de priorizar as que forem de interesse e dentro das condições das instituições.

(4) A comissão de especialistas de ensino de Pedagogia foi recomposta em 2000 sendo constituída pelos seguintes professores: Helena Costa Lopes de Freitas (Unicamp), Maisa Gomes Brandão Kullok (UFAL), Marlene Gonçalves (UFMG), Olga Teixeira Damis (UFU) e Merion Campos Bordas (UFRGS). 


\title{
O processo de elaboração das Diretrizes Curriculares Nacionais para o curso de Pedagogia
}

Em 2002, o governo extinguiu o trabalho de especialistas e em 2003, o CNE designou uma comissão Bicameral para definir as Diretrizes Curriculares Nacionais para o curso de Pedagogia, sendo tal comissão recomposta em 2004. Em março de 2005, a comissão divulgou a primeira proposta de resolução para a apreciação da comunidade acadêmica. O foco da proposta era definir o curso de Pedagogia como uma licenciatura, destinada à formação dos professores para atuarem na Educação Infantil e nos anos iniciais do Ensino Fundamental. Tal proposta parecia reduzir o curso de Pedagogia com propósitos próximos aos do curso normal superior, não levando em conta, portanto, as propostas das comissões de especialistas.

Em junho de 2005, entidades organizadoras (Anfope, Cedes, Anped, Forundir) do vii Seminário Nacional Sobre a Formação dos Profissionais da Educação e os educadores presentes apresentaram as suas contribuições para elaboração das Diretrizes Curriculares Nacionais para o curso de Pedagogia que resultou no «Documento Final vii Seminário». Entre elas a compreensão de que a formação do pedagogo deveria seguir os princípios norteadores de:

\begin{abstract}
1) sólida formação teórica, inter e transdisciplinar sobre o fenômeno educacional e seus fundamentos históricos, políticos e sociais, promovendo a articulação e domínio dos saberes para a compreensão crítica da sociedade brasileira e da realidade educacional, e ainda, a apropriação do processo de trabalho pedagógico; 2 ) interação teoria e prática, que resgata a práxis da ação educativa, como elemento inerente ao trabalho pedagógico, tendo a docência como base da formação profissional; a pesquisa como princípio formativo e epistemológico, eixo da organização e desenvolvimento do currículo; 3) gestão democrática e trabalho coletivo como base para a organização do trabalho pedagógico em contextos educativos escolares e não-escolares; 4) compromisso social, ético, político e técnico do profissional da educação, voltado à formação humana e referenciada na concepção sócio-histórica da educação e nas lutas desses profissionais articuladas com os movimentos sociais; 5) articulação entre a formação inicial e a continuada do profissional da educação. (Anfope, Cedes, Anped, Forundir, 2005)
\end{abstract}

Tais princípios retomam as sugestões gestadas pela Comissão de especialistas (2002), acrescentando apenas a articulação entre a formação inicial e continuada da educação. Em relação ao perfil do egresso, retomam o foco na docência, na gestão e na produção e difusão do conhecimento, deixando de fora a atuação docente/técnica em área emergente do campo educacional.

No documento apresentado pelas entidades em 2005 (ANFOPE/ANPEd/CEDES/ FORUMDIR), a ideia de organização curricular a partir de núcleos reaparece, no entanto, com algumas modificações: tal é a sugestão: a) O núcleo de conteúdos básicos voltado à reflexão crítica sobre as relações sociais e culturais, a educação enquanto uma prática social, a escola, a formação e a profissionalização no campo da educação; b) o núcleo de conteúdos relativos à atuação do pedagogo; c) as atividades científico-culturais de enriquecimento curricular; d) A prática pedagógica; e) trabalho de conclusão de curso (TCC). Podemos dizer que entre o documento da comissão de especialistas de 2002 e o documento enviado à CNE em 2005 pelas entidades participantes do seminário nacional sobre a formação dos profissionais da educação, existiram poucas mudanças. No entanto, é possível perceber em ambos os documentos uma ênfase na profissionalização do pedagogo, na compreensão da Pedagogia centrada na docência, ênfase na docência na Educação Infantil e nos anos iniciais, preocupação com a gestão democrática, foco no estudo das relações educação e trabalho, preocupação com a valorização do magistério e com a formação continuada, necessidade de melhoria da escola básica, a perspectiva de uma formação do pedagogo para atender as demandas sociais, com- 
preensão da docência como trabalho pedagógico construído no conjunto das relações sociais e produtivas, e destaque para a formação de um profissional crítico da sociedade. As propostas se apoiam na compreensão de que o pedagogo precisaria atender as demandas profissionais da sociedade, principalmente da escola básica e, ao mesmo tempo, ter uma postura crítica articulada com os movimentos sociais.

Em dezembro de 2005, o CNE aprovou o parecer CNE/CP n. 05/2005 sobre as Diretrizes Curriculares Nacionais para o curso de Pedagogia, considerando a maioria das propostas das entidades envolvidas, como a ampliação da formação do pedagogo que passa a ser para a docência, gestão e atividades pedagógicas em contextos escolares e não-escolares. Além disso, considerou a tradição da maioria das instituições de ensino superior de formar o pedagogo com foco na formação docente para atuar na educação básica. Entretanto, com a divergência apontada por um dos conselheiros em relação ao artigo 14 da Resolução, que diz ser a formação dos demais profissionais realizada em cursos de pós-graduação, diferente do que está na Lei n. 9.394/96, o parecer foi reexaminado, levando à elaboração do parecer CNE/CP n. 3/2006.

As Diretrizes Curriculares Nacionais para o Curso de Pedagogia foram consolidadas nos Pareceres CNE/CP n. 05/2005, n. 01/2006 e na Resolução CNE/CP n. 01/2006. Iniciaram-se, nesse momento, novos debates que retomam os antigos sem prazo para encerrar. Muitas questões, dúvidas e polêmicas ainda são objeto de análise de pesquisadores e educadores que se envolvem com a Pedagogia, pois como afirma Aguiar et al. (2006, p. 836):

Com a aprovação das Diretrizes, não se extinguem as polêmicas que acompanha as discussões sobre seu caráter e a identidade do curso de pedagogia. O enfrentamento dessas questões não é tarefa para uma ou outra entidade, mas desafio para a área da educação, para a investigação e a pesquisas interdisciplinares, compartilhadas a muitas mãos.

O próprio Parecer CNE/CP n. 05/2005 anunciou que seria necessário dar continuidade à discussão epistemológica que, como vimos, acabou sendo secundarizada por questões sobre a profissionalização do pedagogo. Porém, baseada em Kuenzer e Rodrigues, Scheibe lembra que essa discussão não pode recair na epistemologia da prática, a qual é «predominante na epistemologia da reforma educacional oficial, na qual se vincula o conhecimento formativo a uma prática imediatista» (2007, p. 60). E ainda, o conselheiro do CNE, Francisco Aparecido Cordão, apesar de ter votado favoravelmente ao parecer 5/2005, apontou uma contradição no que se refere à definição do pedagogo. Diz ele: «essa definição, que afirma inicialmente ser o pedagogo o professor da educação infantil e dos anos iniciais do ensino fundamental, reveste em seguida esse profissional de atributos adicionais que deformam consideravelmente o seu perfil» (CNE, 2005).

Tais Diretrizes definiram os princípios, as áreas de atuação e abrangência da formação em Pedagogia.

Aplicam-se à formação inicial para o exercício da docência na educação infantil e nos anos iniciais do ensino fundamental, nos cursos de ensino médio, na modalidade normal, e em cursos de educação profissional na área de serviços e apoio escolar, bem como em outras áreas nas quais sejam previstos conhecimentos pedagógicos. (Brasil, 2006, p. 1)

As DCNs determinaram a extinção do Curso Normal Superior, atribuindo ao curso de Pedagogia a missão de formar os professores dos primeiros anos de escolarização. Direcionam a formação do pedagogo com base no exercício na docência nas diferentes modalidades, articulando, no entanto, com as atividades de gestão e pesquisa educacional. A ideia é formar o pedagogo a partir de 3 pilares indissociáveis: professor, gestor e pesquisador. Segundo o artigo 4 da Resolução, parágrafo único, 
as atividades docentes também compreendem participação na organização e gestão de sistemas e instituições de ensino, englobando: I - planejamento, execução, coordenação, acompanhamento e avaliação de tarefas próprias do setor da Educação; II - planejamento, execução, coordenação, acompanhamento e avaliação de projetos e experiências educativas não-escolares; III - produção e difusão do conhecimento científico-tecnológico do campo educacional, em contextos escolares e não-escolares. (Brasil, 2006, p. 2)

A base da formação é a docência entendida num sentido ampliado que se articula com as atividades pedagógicas a serem desenvolvidas em espaços escolares e nãoescolares. Ou seja, não se busca um docente capaz de ministrar aulas em escolas simplesmente, mas de um docente em condições de trabalhar em diferentes espaços pedagógicos, podendo participar da gestão e produzir conhecimento na área.

Trata-se de Diretrizes aprovadas depois de anos de discussões das diferentes entidades acadêmicas já citadas, agregadas à Comissão de Especialistas do Ensino de Pedagogia e à Comissão de Especialistas de Formação de Professores. Algumas questões parecem ter ficado claras, como a definição do pilar da formação na docência articulada com os ambientes escolares e não-escolares, a participação na gestão e na pesquisa, a compreensão ampliada de docência. A preocupação com a profissionalização do pedagogo assenta o curso na perspectiva da docência, permitindo a correspondência entre o currículo do curso e as tarefas da profissão. Outras questões parecem ainda bastante problemáticas como a indefinição da identidade do pedagogo, áreas de atuação profissional priorizadas pelos cursos, condições de uma formação sólida nas diferentes áreas especificadas e a possibilidade de trabalhar com a multiplicidade de saberes emergentes. Além disso, como assevera Aguiar et al (2006), seria importante considerar outros desafios, tais como:

\footnotetext{
Caminhar na perspectiva de construir efetivamente cursos e percursos de formação no campo da educação e da pedagogia, para formar profissionais que atuarão na educação básica, na formação de crianças, jovens e adultos, na gestão e organização dos espaços escolares e na elaboração de formas criativas e criadoras para a educação escolar e não-escolar. (p. 836)
}

Diante de novas discussões e movimentos realizados em torno do descontentamento das Diretrizes Nacionais para Formação de Professores da Escola Básica, de 2002, e das Diretrizes Nacionais para os Cursos de Pedagogia de 2006, a necessidade de articular o ensino superior e a escola básica, somados às metas do Plano Nacional de Educação - PNE para o decênio de 2014/2024 que buscam a melhoria na formação inicial e continuada de profissionais do magistério da educação básica5, foi aprovada, em 2015, a Resolução de $n^{\circ} 2$ que institui as Diretrizes Curriculares Nacionais para a Formação Inicial em Nível Superior (cursos de licenciatura, cursos de formação pedagógica para graduados e cursos de segunda licenciatura) e para a formação continuada.

As deliberações realizadas, pincipalmente no âmbito da Conferência Nacional de Educação - Conae, de que participaram a Anfope, Anpae, Anped, Cedes e Forumdir foram decisivas no processo de elaboração das novas DCNs. As compreensões que já vinham sendo defendidas por essas entidades obtiveram reforço na Conae e fizeram parte do processo de elaboração das Diretrizes: reafirmar uma base comum nacional para a formação inicial e continuada por meio da garantia de concepção de formação pautada pelo desenvolvimento de sólida formação teórica e interdisciplinar em educação de crianças, adolescentes, jovens e adultos e nas áreas específicas de conhecimento

(5) O Plano Nacional de Educação (PNE) 2014-2020 indica como estratégia da meta 12: «que as instituições deverão assegurar, no mínimo, dez por cento do total de créditos curriculares exigidos para a graduação em programas e projetos de extensão universitária, orientando sua ação, prioritariamente, para áreas de grande pertinência social» (Brasil, 2014). 
científico, estabelecer a unidade entre teoria e prática, ter o trabalho como princípio educativo na formação profissional e a pesquisa como princípio cognitivo e formativo. (Dourado, 2015)

Tendo como foco a melhoria da Educação Básica, as novas DCNs definem que a formação inicial e continuada do profissional do magistério da escola básica deve contemplar uma sólida formação teórica e interdisciplinar dos profissionais; inserção dos estudantes de licenciatura nas instituições de educação básica da rede pública de ensino; o contexto educacional da região onde será desenvolvido; atividades de socialização e avaliação dos impactos; aspectos relacionados à ampliação e ao aperfeiçoamento do uso da língua portuguesa e à capacidade comunicativa, oral e escrita, como elementos fundamentais da formação dos professores e à aprendizagem de Libras; questões socioambientais, éticas, estéticas e relativas à diversidade étnico-racial, de gênero, sexual, religiosa, de faixa geracional e sociocultural como princípios de equidade. (Brasil, 2015)

As DCNs definem que os cursos de formação inicial para os profissionais do magistério para a Educação Básica, em nível superior, compreendem: Cursos de graduação de licenciatura; Cursos de formação pedagógica para graduados não licenciados; Cursos de segunda licenciatura. Consideram-se profissionais do magistério da educação básica aqueles que exercem atividades de docência e demais atividades pedagógicas, incluindo a gestão educacional dos sistemas de ensino e das unidades escolares, nas diversas etapas e modalidades de educação (Educação Infantil, Ensino Fundamental, Ensino Médio, Educação de Jovens e Adultos, Educação Especial, Educação Profissional, Educação Escolar indígena, Educação do Campo, Educação Escolar Quilombola e Educação a Distância). (Brasil, 2015)

Tais Diretrizes buscaram reformular as Diretrizes de 2002, apresentando mudanças significativas, principalmente nos pontos em que houve maior resistência por parte da comunidade acadêmica: tempo de estágio, o foco no conceito de competência, desarticulação dos cursos com a educação básica, pouca ênfase na gestão dos sistemas educacionais, reduzida articulação das Diretrizes Curriculares Nacionais para a Formação Inicial e Continuada, em Nível Superior e as Diretrizes Curriculares Nacionais para a Educação Básica; falta de uma base comum nacional capaz de nortear a formação inicial e continuada no país. Esses indicativos já haviam sido feitos nas Diretrizes de 2006, mas reaparecem nas Diretrizes de 2015 com proeminência. Ou seja, a ênfase na docência é reforçada, não sobrando espaço para a formação do especialista em educação.

Pelo conteúdo das discussões apresentadas, existem avanços significativos na trajetória do curso de Pedagogia que o colocam indubitavelmente no rumo da sua profissionalização e do reconhecimento social. Porém, ao avaliar 144 matrizes curriculares do curso de Pedagogia de São Paulo, entre os anos de 2012 a 2013, Pimenta, Fusari, Pedroso e Pinto (2017) chegam a uma conclusão preocupante sobre os efeitos das Diretrizes na matriz desses cursos:

As matrizes curriculares dos cursos de pedagogia refletem os mesmos problemas identificados nas DCN, ou seja, a indefinição do campo pedagógico e a dispersão do objeto da pedagogia e da atuação profissional docente. Consequentemente, a maioria desses cursos não dão conta de formar nem o pedagogo, nem, tampouco, o professor para os anos iniciais da educação básica e para a educação infantil. (p. 28)

Dessa forma, o curso de Pedagogia acabou se estruturando distante do mundo dos sujeitos, colocando-se mais como um espaço de disputa de territórios do que de consenso legítimo alcançado pela força do melhor argumento alicerçado nas exigências 
práticas vividas, o que Göergen (2008) chama de paroquialismo da formação, ou seja, «o foco exagerado nos problemas de seu entorno imediato» (p. 811).

Diante do diagnóstico dos desacordos sobre a trajetória recente do curso de Pedagogia no Brasil, observamos, na perspectiva da racionalidade comunicativa, a possibilidade de rearticular as discussões sobre os seus propósitos. Propomos repensar a dispersão da formação do pedagogo como um problema advindo dos rumos tomados pela modernidade cultural, os quais exigem uma reconstrução teórica. Por isso, a partir da proposta do agir comunicativo de Habermas, entendido como um potencial teórico capaz de esclarecer as suas incompreensões e as suas direções, entendemos que a referência aos elementos estruturantes do mundo da vida, desvelados como uma précompreensão, permitiria que os acertos tivessem uma aceitabilidade mais alargada. Deixar de considerar o pano de fundo das práticas que compartilhamos é impedir que o entendimento seja alcançado pela via das certezas universais e coibir a falibilidade de nossas interpretações críticas de mundo.

\title{
O agir comunicativo na perspectiva dos pilares da formação
}

Retomando a teoria de Jürgen Habermas como vetor interpretativo da modernidade inacabada, o agir comunicativo oportuniza a transmissão e a renovação do saber cultural, a integração social e a geração de solidariedade, bem como a formação de identidades pessoais. Segundo Habermas (2012),

\begin{abstract}
o processo de reprodução consegue ligar situações novas aos estados do mundo da vida já existentes, seja na dimensão semântica dos significados e dos conteúdos (da tradição cultural), seja nas dimensões do espaço social (de grupos socialmente integrados), seja no tempo histórico (das gerações que se sucedem). (Habermas, 2012, p. 252)
\end{abstract}

Ainda com referência às necessidades da vida, os sujeitos comunicativos reproduzem, mediante suas realizações de entendimento, o saber cultural do qual nutrem a sua identidade e a pertença a coletividades. A dimensão cultural permite que as novas situações que surgem na dimensão semântica possam ser conectadas aos estados de mundo existentes, garantindo a continuidade da tradição e a coerência do saber, mediadas pela racionalidade do saber aceito como válido, necessário à pratica cotidiana. Os entraves na reprodução cultural, que levam à perda de sentido ou a crises de orientação, acontecem quando o saber dos atores não consegue cobrir as necessidades de entendimento exigidas numa nova situação.

\section{A dimensão do espaço social permite}

\begin{abstract}
a integração social do mundo da vida, assegurando a conexão das novas situações a estados de mundos existentes, ou seja, ela cuida para que haja a coordenação de ações por meio de relações interpessoais legitimamente reguladas e pereniza a identidade dos grupos numa medida adequada à prática cotidiana. (Habermas, 2012, p. 257)
\end{abstract}

Nos entraves da integração social que se manifestam por meio de conflitos, os atores já não conseguem suprir a necessidade de coordenação resultante de novas situações, pois as pertenças sociais legitimamente reguladas se tornam insuficientes e a solidariedade fica estancada. A socialização, nesse caso, dos membros de tal contexto constitui

\footnotetext{
a garantia de que novas situações surgidas na dimensão do tempo histórico possam ser conectadas aos estados de mundo existentes, pois graças a elas as histórias de vida individuais podem se afinar com as formas de vida coletivas, e as gerações vindouras poderão adquirir capacidades de ação generalizadas. Capacidades interativas e estilos da conduta de vida se medem pela imputabilidade das pessoas. (Habermas, 2012, pp. 257-258)
} 
Em caso de entraves da socialização, os atores não são capazes de manter a intersubjetividade das situações definidas comuns e a personalidade não consegue manter a sua identidade. Assim, se

a cultura oferece um saber válido capaz de suprir a necessidade de entendimento num mundo da vida, as contribuições da reprodução cultural para a manutenção dos outros dois componentes consistem, de um lado, em legitimações para as instituições existentes, e de outro, em padrões de comportamento para a aquisição de capacidade para ações generalizadas, eficazes do ponto de vista da ação (Habermas, 2012, pp. 258)

Permitindo a reprodução cultural, como continuação e crítica da aquisição e renovação do saber cultural, a integração social surge como coordenação de ações por meio de pretensões de validade reconhecidas intersubjetivamente e a socialização como mediadora da formação da identidade. Porém, a verdade que surge das deliberações sobre a prática cotidiana não garante a sua perenidade:

A verdade, produzida de forma cooperativa pelo discurso, pode oferecer confiança às práticas cotidianas e manter-se como verdade por um determinado tempo. Mas nada assegurará sua validade. A qualquer momento poderá ser questionada, caso não sirva mais para assegurar a reprodução do mundo da vida. Essa permanente capacidade de revalidação da verdade que se faz presente no mundo da vida Habermas atribui a uma certa condição quase transcendental da linguagem. (Mühl, 2010, p. 248)

Ainda segundo Mühl, é esse aspecto que diferencia a teoria de Habermas das propostas pós-modernas e mesmo neopragmáticas sobre a modernidade, pois não há uma radicalização ou redução da verdade a contextos específicos, e sim a sua ampliação para pretensões de validade que podem ultrapassar essas realidades em direção à universalidade. Afinal, complementa Mühl (2010): «Pois, enquanto não nos tornamos bestas, anjos ou robôs, o mundo da vida continuará sendo a instância derradeira de retomada constante dos nossos conhecimentos e de nossos valores» (p. 253).

Desse modo, fica garantido o ideal de universidade comprometido com a relação entre o universal e o local ao mesmo tempo, a parte e o todo integrados de forma complexa, o que evita as patologias da comunicação, conforme refere Göergen: «A qualidade e a pertinência social do ensino procedem da interatuação entre critérios universais, lidos e interpretados à luz da inserção espácio-temporal da instituição, que presumivelmente, será o âmbito de atuação dos futuros profissionais» (2008, p. 811). Trata-se de uma proposta que pode orientar as futuras decisões sobre o curso de Pedagogia para além dos contextualistmos e perspectivismos acadêmicos, potencializando aprendizagem no campo a partir de condições mais supostamente reais.

Considerando que, para Habermas, o agir comunicativo alicerçado nos três elementos estruturantes desse universo permite a sua continuidade (reprodução cultural, integração social e socialização), pode-se inferir que a ausência desses pilares formativos no curso de Pedagogia ao mesmo tempo pode ser motivo da sua transformação em uma espécie de container das vontades e interesses específicos, o que o fragmentou em diversas funções profissionais e docentes.

O problema da dispersão da identidade do curso, que aparece nas Diretrizes, ganha aqui um novo sentido, posto que reside na cristalização da sua proposta na verdade dos discursos, sem observar atentamente a sua relevância para o entorno da demanda da vida. A perda do vínculo com esse saber de fundo pode ser responsável pela falta de relação com a universalidade do campo, ocasionando a fragmentação do seu processo de conclusão, que, conforme denota Scheibe (2007), ainda persiste nas Diretrizes. 


\section{Notas finais}

O que o conceito de mundo da vida, segundo a teoria de Habermas, pode acrescentar ao que já foi dito/feito no decorrer na trajetória de estruturação do curso, especialmente em relação às Diretrizes? O que o conceito de mundo da vida entendido como panode-fundo, como um saber não tematizado, que pode voltar circunstancialmente quando o discurso se torna problemático, traz de contribuição para o tratamento da problemática do curso de pedagogia? Ora, a visão da qualidade formativa da educação institucional está pautada em uma formação de pedagogos com enfoque cada vez mais alheio às necessidades formativas mais amplas do sujeito, bem como num bloqueio da sua história como área do conhecimento. Quando essas certezas se tornam problemáticas, é necessário migrar as questões da experiência prática para o discurso e, a seguir, se confrontar com a sua «eficácia pragmática». Portanto, a referência aos interesses ancorados em uma suposta objetividade comum permite balizar as discussões sobre a dispersão do campo da Pedagogia rumo a uma aceitabilidade mais ampliada e, provavelmente, a um desfecho para além da preocupação com a empregabilidade, embora isso seja muito importante. Essa postura, provavelmente, permitiria ao curso repensar a sua identidade como área de conhecimento, coordenar as suas ações em torno da formação docente, e reestruturar a profissionalização dos professores para a educação infantil e anos iniciais ainda desprovida de especialização.

Parece que na tentativa de resistir à política neoliberal focada na profissionalização exclusivamente técnica, fruto de um desvirtuamento da modernidade cultural, o curso acabou se desarticulando das necessidades práticas do mundo da vida. Nesse sentido, entendemos que, pela via do agir comunicativo, é possível evitar decisões tendenciosas, interessadas e reduzidas da complexidade do sistema, e se utilizar do pano de fundo das práticas compartilhadas por todos, segundo o qual é possível alcançar o entendimento sobre o assunto. Isso porque, «na sociedade contemporânea, já não existem temas e problemas que não tenham, sempre, também imbricações e ressonância de mundo, de universalidade, de totalidade» (Göergen, 2008, p. 811). Se a Pedagogia percorreu caminhos instáveis, é necessário rearticulá-la às perspectivas de referências universalizadas para, só então, ter o seu entendimento mais corretamente restabelecido. Assumindo o compromisso com o todo linguístico, é possível esclarecer melhor a sua orientação, desenvolvendo uma cultura de corresponsabilidade diante da sua história. Ao se utilizar de pretensões de validade universais, a discussão seria conduzida pela força do melhor argumento, não mais por interesses subjetivos e/ou instrumentais, ficando sempre, portanto, em coerência com o seu campo de conhecimento já produzido.

Tal atitude conteria os monopólios interpretativos, retomando a capacidade integradora da pluralidade de esferas de valores, oferecendo subsídios para enriquecer as discussões sobre o curso com possibilidades de acertos descentrados. O saber cultural, a integração social e a formação de identidades serviriam como um repertório de salvaguarda à unidade na multiplicidade histórica e interpretativa do campo pedagógico, prevenindo o risco de redução das discussões às forças burocráticas da lógica do sistema. Isso significaria reavivar o compromisso da pedagogia com a sua identidade epistemológica que, a nosso ver, não se reduz somente ao conceito de docência, mas o integra à pesquisa permanentemente. Além disso, o campo poderia ser preservado da perda de identidade, tendo em vista a possibilidade de recuperação do sentido diante das aceitabilidades compartilhadas. 


\section{Referências}

Aguiar, M., Brzezinsk, l., et. al. (2006) «Diretrizes curriculares do curso de pedagogia no Brasil: disputas de projetos no campo da formaçãa do profissional da educaçãa». Educação e Sociedade, vol. 27, n. 96 - Especial, pp. 819-842.

ANFOPE (1998) IX Encontro nacional: documento final. Campinas.

ANFOPE/ANPEd/CEDES/FORUMDIR - Documento Final VII Seminário. Brasília, 2005.

Azevedo, F., et.al. (2006) «O manifesto dos pioneiros da educação nova». Revista Histedbr, n. especial, pp. 188-204.

Brasil (1996) Lei de Diretrizes e B. Lei no 9.394/96, de 20 de dezembro de 1996.

Brasil (2002) Conselho Nacional de Educação. Resolução CNE/CP1, de 18/2/2002.

Brasil (2006) Conselho Nacional de Educação. Parecer CNE/CP 5, 13.12.2005. Brasília, 2005. Resolução n.1, 15.5.2006. Diário Oficial da União, n.92, seção 1, p.11-12, 16 maio 2006.

Brasil (2014) Plano Nacional de Educação - Lei n 13.005/2014.

Brasil (2015) Conselho Nacional de Educação. Resolução n. 2. 01/07/2015.

Brzezinski, I. (2013) Pedagogia, pedagogos e formação de professores. Campinas, Papiros.

Brzezinski, I. (2008) «Políticas contemporâneas de formacão de professores para os anos iniciais do ensino fundamental». Educação e Sociedade, vol. 29, n. 105, pp. 11391166.

Comissão de especialistas de ensino de pedagogia (1999) Proposta de diretrizes curriculares para o curso de pedagogia. Brasília, MEC-Sesu.

Comissão de especialistas de ensino de pedagogia, Comissão de especialistas de formação de professores (2002) Proposta de diretrizes curriculares nacionais para o curso de graduação em Pedagogia. Brasília.

Cruz, G. B. da (2011) Curso de pedagogia no Brasil: história e formação com pedagogos primordiais. Rio de Janeiro, Wak Editora.

Decreto no.9.268-A, de 25 de junho de 1938. Extingue o Instituto de Educação da USP.

Dourado, L. (2015) «Diretrizes curriculares nacionais para a formação inicial e continuada dos profissionais do magistério da educação básica: concepções e desafios». Educação e Sociedade, v. 36, no. 131, pp. 299-324.

Franco, M. A. S., Libâneo, J. C., Pimenta, S. G. (2007) «Elementos para a formulação de diretrizes curriculares para cursos de pedagogia». Cadernos de Pesquisa, v. 37, n. 130, p. 63-97.

Gatti, B. (2010) Formação de professores no Brasil: características e problemas. Educação e Sociedade, Campinas, v. 31, n. 113, pp. 1355-1379, out.-dez.

Göergen, P. (2008) «Educação superior entre formação e performance». Revista Avaliação, v. 13, n. 3, pp. 809-815.

Habermas, J. (2012) Teoria do agir comunicativo: sobre a crítica da razão funcionalista. São Paulo, Martins Fontes.

Libâneo, J. C. (2013) Pedagogia e pedagogos: para que? São Paulo, Cortez.

Mühl, E. (2010) «Vida, mundo da vida e educação: uma leitura habermasiana do problema da justificação da ação educativa», en Trevisan, A. L., Tomazetti, E. M., Rossatto, N. D. (Ed.) Diferença, cultura e educação. Porto Alegre, Sulina, pp. 240-253.

Pimenta, S. G., Fusari, J. C., Pedroso, C. C. A., Pinto, U. de A. (2017) «Os cursos de licenciatura em pedagogia: fragilidades na formação inicial do professor polivalente». Revista Educação e Pesquisa, v. 43, n. 1, pp. 15-30.

Saviani, D. (2012) A Pedagogia no Brasil: história e teoria. Campinas, Autores Associados.

Scheibe, L. (2007) «Diretrizes curriculares para o curso de Pedagogia: trajetória longa e inconclusa». Cadernos de Pesquisa, v. 37, n. 130, pp. 43-62.

Scheibe, L.; Durli, Z. (2011) «Curso de Pedagogia no Brasil: olhando o passado, compreendendo o presente». Educação em Foco, v.1, n. 17, pp. 79-109.

Silva, C. S. B. da (2006) Curso de Pedagogia no Brasil: história e identidade. Campinas, Autores associados. 


\section{Entre els encerts i desencerts dels estudis de pedagogia al Brasil: reflexions sobre la necessitat d'articulació a partir de les demandes del món de la vida}

Resum: Aquest article que és de naturalesa hermenèutica-reconstructiva discuteix, a partir de la constitució dels estudis universitaris, la identitat professional del pedagog que roman pressionat o tensionat entre la docència, territori de formació de professors i, la pròpia àrea de coneixement. Primerament, aborda la proposta com a possibilitat de repensar la trajectòria dels estudis comunicativament per mitjà de la referència als elements constitutius pel món de la vida (reproducció cultural, integració social i socialització). Seguidament, presenta la trajectòria històrica de les discussions sobre la carrera de Pedagogia al Brasil amb èmfasi en la institucionalització de les seves directrius. Finalment, es discuteix el fonament del món de la vida d'una manera crítica a les prerrogatives guiades amb prou feines només per l'interès de discursos per auxiliar en el fet de qüestionar algunes certeses que acabessin prevalent en la definició dels camins del curs de Pedagogia.

Paraules Clau: Pedagogia, acció comunicativa, món de la vida.

\section{Entre les succès et les échecs des études de pédagogie au Brésil: réflexions sur la nécessité d'une articulation autour des demandes du monde de la vie}

Résumé: Cet article, de nature herméneutique-reconstructive, traite de l'identité professionnelle du pédagogue à partir de la constitution des études de pédagogie, qui se débat entre l'enseignement - le territoire de la formation des enseignants - et le domaine de la connaissance. Tout d'abord, il aborde la proposition comme une possibilité de repenser le parcours des études de manière communicative par référence aux éléments constitutifs du monde de la vie (reproduction culturelle, intégration sociale et socialisation). Ensuite, il présente le parcours historique des discussions sur la carrière de pédagogie au Brésil, en mettant l'accent sur l'institutionnalisation de ses lignes directrices. Enfin, il examine le fondement du monde de la vie de manière critique à l'égard des prérogatives guidées seulement par des intérêts de discours pour aider à remettre en cause certaines certitudes qui ont fini par prévaloir dans la définition des directions des études de pédagogie.

Mots-clés: Pédagogie, action communicative, monde de la vie.

\section{Successes and failures of pedagogy courses in Brazil: reflections on the need to bring them into line with the demands of the world of life}

Abstract: This hermeneutic-reconstructive article discusses the professional identity of the teacher from the constitution of pedagogy courses, with the inherent tension of their conception either as an activity focused on training new teachers or as one exploring an area of knowledge. First, it proposes a communicative reappraisal of pedagogy courses by referring to the constitutive elements of the world of life (cultural reproduction, social integration and socialization). Next, it presents the history and the trajectory of the discussions about the course of pedagogy in Brazil, with an emphasis on the institutionalization of its guidelines. Finally, it presents a critical discussion of the foundation of the world of life as the prerogatives guided only by interests of discourses in order to help in the questioning of certain ideas that finally prevailed in the definition of the directions of the course of Pedagogy.

Keywords: Pedagogy, Communicative Action, World of life. 